\title{
Anesthetic management for laryngeal closure: retrospective evaluation of 50
} cases

\author{
Midori Mogami ${ }^{1}$, Chiaki Nemoto ${ }^{1 *}$, Makoto Kano², Mariko Muto ${ }^{1}$, Youichi Tanaka ${ }^{1}$ and Mashahiro Murakawa ${ }^{3}$
}

Keywords: Laryngeal closure, Aspiration pneumonia, Malnutrition

\section{Background}

Laryngeal closure is effective in patients who suffer from repeated aspiration pneumonia [1]. Most patients who require this surgery, however, present with malnutrition or are relatively dehydrated either because of aspiration pneumonia or their primary disease. We report our anesthetic management protocol and discuss the problems encountered in these patients.

\section{Case presentation}

After obtaining approval from the hospital's ethics committee, we evaluated the medical records of patients who underwent surgical closure of the larynx in our hospital from January 2013 to January 2015. The patients comprised 35 men and 15 women with a mean body mass index of $18 \pm 3.9 \mathrm{~kg} / \mathrm{m}^{2}$ and mean age of 71 \pm 18.4 years. Most patients had malnutrition, with a serum albumin level of $2.7 \pm 0.7 \mathrm{~g} / \mathrm{dl}$ and serum sodium level of $136.0 \pm 5.4 \mathrm{mEq} / \mathrm{l}$. Their primary diseases varied as shown in Table 1. In total, $17(34 \%)$ of the patients had already undergone tracheostomy, and oral tracheal intubation was performed in two others. Two patients required mechanical ventilation. Preoperative blood gas analysis showed a $\mathrm{PaO}_{2}$ of $88.6 \pm 23.9 \mathrm{mmHg}$ and $\mathrm{PaCO}_{2}$ of $41.7 \pm 5.7 \mathrm{mmHg}$.

The operation time was $158.4 \pm 24.6 \mathrm{~min}$, and the duration of anesthesia was $202.5 \pm 27.1 \mathrm{~min}$. The anesthetic induction agents varied among the patients: sevoflurane was used in 36 patients, midazolam in 7 , propofol in 5, and thiopental in 1. In most patients, general anesthesia was maintained by sevoflurane and remifentanil.

\footnotetext{
*Correspondence: nemo@fmu.ac.jp

'Department of Anesthesiology, Ohara General Hospital, 6-11 Ohomachi,

Fukushima 960-8611, Japan

Full list of author information is available at the end of the article
}

Target-controlled infusion by propofol and remifentanil was performed in only one patient, who had amyotrophic lateral sclerosis. Rocuronium was administered in all patients. In 30 patients, rocuronium was administered only at the time of tracheal intubation. Additional doses of rocuronium were needed in 20 patients. The mean induction dose of rocuronium was $0.79 \pm 0.16 \mathrm{mg} / \mathrm{kg}$, with additional doses of $0.42 \pm 0.34 \mathrm{mg} / \mathrm{kg}$ as needed. During anesthesia, 38 patients required a cardiovascular agent. Among them, 11 (22\%) were given ephedrine and 33 (66\%) were given phenylephrine. Continuous administration of noradrenaline was performed in two patients and dopamine hydrochloride in one patient. Forty-two patients (84\%) required reversal of rocuronium using sugammadex sodium, and eight patients (16\%) were given naloxone because of delayed emergence of spontaneous breathing. With the exception of two patients who were ventilated before the operation, none of the patients required mechanical ventilation during the postoperative period. Postoperative pain management with acetaminophen or non-steroidal anti-inflammatory drugs was satisfactory.

\section{Discussion}

Laryngeal closure lessens the risk of aspiration, making it possible for the patients to improve their nutritional condition. Malnutrition and/or hyponatremia are serious perioperative complications for these patients. Malnutrition is a possible factor associated with anastomotic leakage [2]. No patients who underwent laryngeal closure under general anesthesia in our hospital required re-operation due to anastomotic leakage.

Some of the patients had hyponatremia, which is sometimes found in elderly patients [3]. The mean preoperative sodium concentration was $136 \pm 5.4 \mathrm{mEq} / \mathrm{l}$ in our patients, although five (10\%) patients had a sodium 
Table 1 Patients' primary diseases

\begin{tabular}{lllc}
\hline & $\begin{array}{l}\text { Total } \\
\text { numbers }\end{array}$ & $\begin{array}{l}\text { Post- } \\
\text { tracheotomy }\end{array}$ & Intubated \\
\hline Parkinson's disease & 10 & 2 & 1 \\
Cerebral hemorrhage & 9 & 5 & \\
Cerebral infarction & 9 & 5 & 1 \\
Cerebral palsy & 5 & & \\
Multiple system atrophy & 2 & 2 & \\
Amyotrophic lateral sclerosis & 2 & 1 & \\
Dementia & 3 & & \\
Disuse syndrome & 10 & 2 &
\end{tabular}

Disuse syndrome: postoperative dissecting aneurysm $(n=1)$, postoperative major abdominal surgery $(n=3)$, hypoxic brain damage due to suffocation $(n=1)$, pneumonia $(n=5)$

level of $<130 \mathrm{mEq} / \mathrm{l}$. Radical perioperative fluid therapy could raise the sodium concentration to a point that causes osmotic demyelination syndrome [4]. We administered 1\% glucose lactated Ringer's solution (2.9 $\pm 1.1 \mathrm{ml} / \mathrm{kg} / \mathrm{h}$ ) during anesthesia in our patients. Surgical closure of the larynx poses little risk of massive bleeding. However, these patients were chronically dehydrated, so fluid administration was increased during the perioperative period.

During anesthesia, some of the patients have experienced hypotension. Malnutrition and chronically dehydrated state were possible factors of hypotension especially in elder patients. In most cases, we could manage by intermittent administration of ephedrine and phenylephrine.

In the operating rooms, emergence from anesthesia might be delayed by remifentanil; however, no patients showed respiratory suppression in the recovery room. In some patients who need this operation, the primary disease causes a consciousness disorder, which was present before anesthesia. Therefore, the use of drugs that could affect their respiratory condition or state of consciousness should be carefully considered. Although the effect of remifentanil is short, even in patients with renal or hepatic failure [5], reversal drugs might be needed because of delayed emergence from anesthesia. None of our patients developed a worsened respiratory condition postoperatively.

\section{Conclusions}

Patients who require laryngeal closure present with several preoperative problems due to repeated aspiration pneumonia or their primary disease. Despite these problems, no serious complications associated with general anesthesia were found in our hospital.
Authors' contributions

All operations were performed by MK. MM mainly wrote the manuscript. CN, MM, and YT participated in data collection and analysis and drafted the article. All authors read and approved the final manuscript.

Ethics approval and consent to participate

This study was approved by the ethics committee of Ohara General Hospital (approval number 145).

Competing interests

The authors declare that they have no competing interests.

\section{Publisher's Note}

Springer Nature remains neutral with regard to jurisdictional claims in published maps and institutional affiliations.

\section{Author details}

${ }^{1}$ Department of Anesthesiology, Ohara General Hospital, 6-11 Ohomachi, Fukushima 960-8611, Japan. ' 2 Department of Otorhinolaryngology, Head and Neck, Ohara General Hospital, 6-11 Ohmachi, Fukushima 960-8611, Japan.

${ }^{3}$ Department of Anesthesiology, Fukushima Medical University School of

Medicine, 1 Hikarigaoka, Fukushima 960-1295, Japan.

Received: 4 December 2017 Accepted: 17 December 2017

Published online: 22 December 2017

References

1. Montgomery WW. Surgical laryngeal closure to eliminate chronic aspiration. N Engl J Med. 1975;292:1390-1

2. Eisele DW. Surgical approaches to aspiration. Dysphagia. 1991;6:71-8.

3. Upadhyay A, Jaber BL, Madias NE. Incidence and prevalence of hyponatremia. Am J Med. 2006;119(Suppl 1):S30-5.

4. Canaday S, Rompala J, Rowles J, Fisher J, Holt D. Chronic severe hyponatremia and cardiopulmonary bypass: avoiding osmotic demyelination syndrome. J Extra Corpor Technol. 2015;47:228-30.

5. Michelsen LG, Hug CC Jr. The pharmacokinetics of remifentanil. J Clin Anesth. 1996:8:679-82.

\section{Submit your manuscript to a SpringerOpen ${ }^{\circ}$ journal and benefit from:}

- Convenient online submission

Rigorous peer review

- Open access: articles freely available online

- High visibility within the field

- Retaining the copyright to your article

Submit your next manuscript at $>$ springeropen.com 